\title{
D. H. Lawrence en Oaxaca
}

\section{$\mathbf{I}$}

F ${ }^{\mathrm{N}}$ dos ocasiones visitó D. H. Lawrence a la República Mexicana: la primera vez en 1923 y la segunda en 1924. En octubre de este último año, Lawrence y su esposa permanecieron algunos dias en la ciudad de México, instalándose en el Hotel Monte Carlo, donde se habían alojado en su primera visita. Seis meses antes, al salir de Inglaterra, Lawrence había invitado a Middleton Murry, a Catherine Carswell y a varios otros amigos a que lo acompañaran en su viaje a América. Pero cuando los esposos Lawrence al fin se embarcaron rumbo a Nueva York en el "Aquitania", por única compañera tenían a Dorothy Brett, pintora y amiga de Katherine Mansfield. Los tres pasaron el verano en Kiowa, el rancho de Nuevo México que Mabel Dogle Luhan había cedido a Frieda Lawrence a cambio del manuscrito del libro Hijos y amantes.

Durante su permanencia en la ciudad de México, los Lawrence asistieron a un almuerzo donde Frieda estuvo sentada al lado de W. Somerset Maugham. Este encuentro lo describió Frieda en los términos siguientes:

"Yo sentí lástima de Maugham. Me pareció que era un hombre desdichado y amargado, que no sabía gozar de la vida... No podia aclimatarse al estrecho mundo social y, sin embargo, no creía en otro más amplio y humano... Cuando llegué a conocer a otros escritores, entonces comprendí inconscientemente cuán totalmente diferente era Lawrence. Bien podian ellos ser buenos escritores, pero Lawrence era un genio." 1 
El trozo citado, aunque es claramente injusto para con Somerset Maugham, constituye una grata revelación del respeto que profesaba Frieda a su marido en cuanto artista. En cambio, fué, según creo, el sentimiento de su propia inferioridad frente a Maugham, en ciertos aspectos, lo que movió a Lawrence a escribir en carta dirigida a "Spud" Johnson lo siguiente: "Willie M- me ha telegrafiado. Se ha ido a Cuernavaca 'para trabajar'. ¡Malditos sean sus ojos y su trabajo!" 2 Y en otra carta escrita a Witter Bynner:

\footnotetext{
“ salió para Cuernavaca el día en que nosotros llegamos, pero según parece, él también está un poco echado a perder. Antipático, sin chispa de buen humor, y temblando de miedo de que no pueda escribir antes de las Navidades su próximo gran libro de brillante fondo mexicano. Un 'artista' apocado y tartamudo." 3
}

Y aun er otra carta dirigida a Curtis Brown: "Conocimos a en la ciudad de México. No le gusta nada la vida de aquí. Se ha ido a Yucatán. Tampoco le ha de gustar la vida de allá. Me cayó mal el hombre. Un poco avinagrado." 4 Todo esto es cruel, pero no hay mayor crueldad que la que procede de la debilidad. Lawrence, a pesar de todo su brillo y tenacidad, se hallaba confuso ante la vida; y su confusión se ve reflejada en sus obras. Maugham aceptaba la vida tal como es y la dramatizó en una serie de obras maestras noveladas. Pero Lawrence, al igual que Maugham, era un hombre valeroso, $y$ he aqui por qué le perdonamos todo.

En el mes de noviembre los esposos Lawrence y "Brett", como se apellida esta señora en su libro titulado Lawrence y Brett, partieron rumbo a Oaxaca.

A fines del otoño de 1924, Lawrence, Frieda y Brett, al llegar a Oaxaca, fueron a parar al Hotel Francia. Lawrence, que había soportado con dificultad la altura de casi 9,000 pies que tenía su rancho de Nuevo México, esperaba que le convendría más el clima tropical de Oaxaca, que sólo tenia unos 5,000 pies sobre el nivel del mar. Los tres amigos siguieron su viaje desde la estación del ferrocarril hasta el hotel en un tranvía tirado por mulas. La dueña del hotel les advirtió a sus huéspedes que guardaran su equipaje en sitio lo 
más apartado posible de las ventanas, porque de otro modo sus objetos podrían ser robados por ladrones armados de largos palos con ganchos.

Lawrence escribió a Curtis Brown, su representante de Londres, diciéndole que Oaxaca estaba llena de sol y de rosas y que él pensaba alquilar una casa en que pasar un par de meses. A su amigo Middleton Murry le escribió a propósito de Oaxaca: "No queda muy lejos ni de una ni otra costa, pero no hay ferrocarril. Se puede ir a caballo hasta el Pacífico o hasta el Atlántico en cuatro o cinco dias - con tal de no ser fusilado." $s$

Mientras que Brett siguió viviendo en el Hotel Francia, los Lawrence alquilaron una casa ubicada en la Avenida Pino Suárez, número 43. Alli terminó Lawrence su novela $L a$ serpiente empluma$d a$, que había empezado el año anterior en Chapala. $\mathrm{Y}$ allí también escribió los ensayos que forman el volumen Las mañanas en México. A veces, cuando vagaba por la ciudad, los indios andaban tras él gritando “ "Cristo! „Cristo!” Y la verdad es que con su palidez ascética y sus ojos de penetrante mirada, debía tener el aspecto de un Cristo de barba roja.

A Brett le encantaba el mercado. "Es oscuro -escribe ellacon grandes manchas de sol... aquí y allá. Hay flores, enormes ramos de flores; legumbres y frutas, limpias y relucientes; sarapes hermosísimos... canastas. ¡Color, color por todas partes!" 6 Pero el olor nauseabundo de los huaraches (sandalias mexicanas) era ya demasiado fuerte para Brett. $\mathrm{Y}$ le robaron su trompetilla acústica, de modo que tuvo que encargar a un hojalatero de la ciudad que le hiciera una improvisada que sirviera hasta que pudiera conseguir otra de Inglaterra.

La casa de los Lawrence tenía un delicioso patio de azulejos rojos, con acogedora sombra. En el huerto había naranjos y plátanos. En uno de estos árboles se posaban dos pericos verdes que solían gritar a un perrillo blanco llamado Corasmin. La casa estaba sin muebles, pero varias personas para quienes Lawrence traia cartas de presentación le prestaron mesas, sillas y camas. Cuidaba la casa un mozo llamado Rosalino. Rosalino no podía cargar cosas pesadas porque le habían baldado a palos por haberse negado a servir de soldado en el ejército de no sé qué revolucionarios. 
Cierto día una india siguió a Lawrence hasta su casa, empeñada en venderle cuatro patos que traía. Para librarse de ella, Lawrence le compró los patos, y Rosalino, muy complaciente, les hizo un estanquillo en el jardín. Lawrence le recompensó con un sarape nuevo que sirviera para protegerlo del frío de la noche cuando dormía en su banca-de madera junto a la puerta de entrada. También comenzó a enseñarle a leer y escribir. Rosalino, imitando a su señor, se bañaba todos los sábados por la noche, y los domingos por la mañana se ponía siempre una camisa limpia y vistosa. Rogaba de continuo a Lawrence que lo llevara consigo cuando volviera a Londres.

Lawrence dedicaba las mañanas a trabajar sobre la versión final de La serpiente emplumada, mientras Brett le servía de mecanógrafa. Era invitado con frecuencia a cenar en casa de una de las familias norteamericanas de Oaxaca. Por regla general aceptaba las invitaciones, pero únicamente a condición de que se sirviera la comida a la hora exacta. No le importaba si cenaban a las siete o a las nueve, pero no le gustaba esperar. Lawrence había llegado a ser un personaje de bastante importancia, hasta en la remota Oaxaca, para poder imponer su voluntad a los demás. Esto se pone aún más de manifiesto por el episodio siguiente, según nos lo refiere Frieda:

"Yo iba siempre al mercado con el mozo y un día me señaló en la plaza, en una de las librerías, una caricatura que no se podia negar era de Lawrence, y me miró a la cara para ver cuál sería mi reacción. Yo me quedé entusiasmada. El hallar en este lugar primitivo, entre indigenas de pura sangre, algo tan civilizado como una caricatura de Lawrence, era cosa bien divertida." 7

En una ocasión el señor Miller, un vecino que vivía al otro lado de la calle, llevó a los Lawrence en su automóvil a Mitla. Salieron de Oaxaca a las seis de la mañana, y llegaron a Mitla seis horas más tarde, después de caminar a paso de tortuga por un camino que entonces era malísimo. Un indio que hacía de guía les enseñó las ruinas. Al contemplar la piedra de sacrificios, percibian con la imaginación el olor de la sangre. Luego, un tanto reanimados por un buen almuerzo que tomaron en el restaurant del lugar, emprendieron el largo viaje de regreso.

Una tarde los Lawrence $-\mathbf{y}$ Brett, naturalmente-, visitaron una alfarería. Alli vieron a un indio muy diestro en modelar una vasija de barro dando vueltas con los pies descalzos a la enorme rue- 
da de piedra. En otra ocasión, Brett, que era sumamente aficionada a las armas blancas, fué sola a la tienda de un indio cuyas espadas y navajas de acero eran conocidos en todo el mundo. También se divertían los amigos escuchando la banda municipal, y en cierta ocasión vieron en el cine del barrio una película en la que Douglas Fairbanks representaba el papel principal. Brett compró una cría de ardilla en jaula. Una noche en que Lawrence y Brett, después de tomar cocteles con unos amigos, llegaron a casa poco después de las nueve, Frieda se enfadó. Esto fué el principio de una lamentable hostilidad que había de ir creciendo entre las dos mujeres.

El día de la fiesta de San Felipe, Lawrence, Frieda y Brett entraron en la iglesia, que según la descripción de Brett, parecía "un mar de indios arrodillados". Al salir de la iglesia, se pusieron a vagar por entre los puestos de los vendedores, y Frieda y Brett comieron "tortillas grandes cubiertas de miel dorada", que se les caía gota a gota por el mentón. Había un carrousel para los niños y como siempre, algunos mendigos sentados al borde del camino.

Ya para entonces Lawrence había comenzado a escribir Mañanas en México. El y Brett tenían por costumbre salir al campo solitario donde se sentaban bajo la sombra de un par de árboles. Allí escribía Lawrence mientras Brett pintaba, bañados por el sol radiante y el aire embalsamado. Cuando Lawrence concluía de escribir, se ponía a criticar el trabajo de Brett y aun trataba de mejorárselo, a pesar de ser él un escritor y ella una pintora.

Estando Brett un día en el mercado con Rosalino, un indio borracho le dió un golpe y Rosalino tuvo que salir a su defensa. En otra ocasión, acompañada de otra señora, asistió a la fiesta de los Rábanos. Ambas mujeres se quedaron algo turbadas al ver, como muñecos colgados en los puestos de los vendedores, grandes rábanos colorados y blancos, que estaban tallados en forma de hombrecitos muy naturales, que tenían ciertas partes del cuerpo bastante agrandadas. A los indios les causó risa la turbación de las damas. En la misma fiesta, imitando a los indios, ellas también compraron vasijas de barro que arrojaban al aire para verlas caer y romperse en mil pedazos, produciendo un ruido muy divertido. El día de Navidad Lawrence cayó tan enfermo que tuvo que guardar cama, pero en sú hogar había un árbol de Navidad. Algunos indios llegaron a su casa 
trayendo objetos de barro como regalos, y a su vez recibieron aguinaldos.

\section{III}

En enero Lawrence escribió a Curtis Brown: "Te envio cuatro artículos, Mañanas en México, bien breves ... Estoy haciendo progreso en la novela mexicana. Con la ayuda del cielo he de terminarla este mes... De veras me gusta mucho." 8

Mientras tanto, la hostilidad entre Frieda y Brett había crecido tanto, que pronto había de estallar la guerra. Frieda describe la situación del modo siguiente: "La Brett venía a casa todos los días y yo pensé que ella iba siendo una parte demasiado importante de nuestra vida y me sentía ofendida por ello. Así que le dije a Lawrence: 'Quiero que se vaya la Brett', y él se enfureció conmigo y me llamó una tonta celosa. Pero yo me empeñé, y así Brett se marchó a la ciudad de México." o

Según la versión de Brett, una mañana Rosalino le trajo a su hotel una carta de Lawrence en la que él decía que los tres ya no formaban "un grupo feliz" y que debían separarse. Al ir a visitarlos a su casa, encontró a Lawrence "con muy mala cara" y a Frieda sentada en una silla con una expresión dura en los ojos y "la boca fruncida". La mesa para té le parecía que estaba "colocada encima de un volcán". Después de volver Brett al hotel, llegó Lawrence "exaltado, enfurecido, desesperado". Ella prometió salir de Oaxaca y él convino en que esto sería lo mejor para todos. Después de esto, Lawrence y Brett siguieron disfrutando por algunos días más de sus paseos y conversaciones. Pero una mañana Frieda le entregó a Brett una carta que ella misma le había escrito en la que acusaba a los dos amigos de conducirse "como un cura y una solterona", y se mostraba ofendida porque no se hacían el amor. Aunque se cambiaron algunas palabras amargas, Brett y Frieda se despidieron una de otra amistosamente. Al dia siguiente, los Lawrence pusieron a Brett a bordo del tren para México. ${ }^{10}$

Las cartas que escribió Lawrence en aquellos días a Middleton Murry expresan la antipatía más violenta tanto hacia el mismo Murry como hacia su revista, Adelphi. Le dice que es posible que vaya a Inglaterra en la primavera pero que no espera ver allí a Murry, porque "con la última vez tuvo más que suficiente". ${ }^{11}$ 
Por fin Lawrence terminó de escribir, o mejor dicho, de corregir su novela mexicana, Quetzalcóatl, a la que se dió más tarde el título de La serpiente emplumada. Mientras tanto, sin embargo, había enfermado gravemente de malaria. En febrero escribió a Curtis Brown:

\begin{abstract}
"He estado pasando las de Caín por culpa de la condenada malaria... La causa el fuerte sol de invierno. (sic) Espero en Dios que podamos ir a México dentro de una semana y salir de las regiones del paludismo. Si tenemos suerte hemos de embarcarnos para Inglaterra en Veracruz el 10 de marzo y desembarcar en Inglaterra alrededor del 25. Traeré conmigo el manuscrito de Quetzalcóatl y tú podrás conseguir que me lo copien a máquina. Entonces yo podré corregirlo. Ya está terminado." 12
\end{abstract}

Frieda mandó llamar a un médico para Lawrence, pero el médico no vino. Los ingleses y norteamericanos que residían en la ciudad hicieron todo lo posible por ayudarles. Lawrence estaba seguro de que iba a ser enterrado en el cementerio del pueblo. "No - dijo Frieda, riéndose-, es un camposanto tan feo que no debes pensar en ello." "Pero si me muero - respondió Lawrence- has de saber que lo único que ha tenido importancia en mi vida has sido tú, sólo tú." 13 Encontramos una humildad conmovedora en las palabras con que Frieda comenta este episodio: "Casi me asusté de oírle decir eso de que, con todo su genio, yo había tenido tanta importancia en su vida. Parecía increíble." 14

Frieda le alivió los dolores con saquitos de arena caliente. La esposa de un misionero, al traer a Lawrence un plato de sopa, se arrodilló junto a su lecho y se puso a rezar por él. A media noche hubo un terremoto, que hizo moverse las vigas del techo y aterrorizó a los caballos, burros, perros y gatos. El viaje a México resultó ser un "via crucis". A Frieda le atormentaba un horrible presentimiento: "Nunca volverá a estar completamente bien de salud. Está enfermo. Está condenado a morir. Todo mi amor, todas mis fuerzas no le devolverán jamás la salud." 15

A principios de marzo, Lawrence escribió desde el Hotel Imperial de México a Curtis Brown:

"Pues bien, de todos modos hemos salido del valle de Oaxaca. Yo estuve alli muy enfermo de malaria e influenza. Hemos de embarcarnos el 17 de marzo en Veracruz a bordo del vapor Río Bravo 
y desembarcar en Plymouth el 3 de abril. Creo que hemos de permanecer algún tiempo en Devonshire para recobrar las fuerzas perdidas, Los médicos dicen que tengo que vivir cerca del mar. Aquí hay una altura excesiva." 16

Entonces sobrevino el desenlace trágico. El médico de la ciudad de México declaró que Lawrence tenía tuberculosis y que sólo podía vivir, a lo sumo, un par de años más. Dice Lawrence en su segunda carta escrita a Curtis Brown:

"Estoy aquí todavía en la cama. El médico me hizo toda clase de reconocimientos: análisis de sangre, etc. Dice que no debo de ninguna manera exponerme a un viaje por mar ni a los rigores del clima de Inglaterra hasta pasados varios meses, y que debo quedarme aquí tomando el sol o ir al rancho. Así pues, en cuanto yo pueda viajar, iremos al rancho. Escribeme alli." 17

Después de una ruda brega con los aduaneros de la frontera, en la que el cónsul inglés tuvo que intervenir, Lawrence y Frieda lograron volver a su rancho, Kiowa, situado entre las montañas de Nuevo México. Así terminó la segunda y última visita que hizo Lawrence al país del otro lado del río Bravo. A este pais dedica los cuatro primeros capítulos del pequeño volumen, Las mañanas en México. ${ }^{18}$

A los cuatro ensayos sobre Oaxaca siguen tres sobre los bailes de los indios de Nuevo México y de Arizona, y un breve ensayo de evocación nostálgica escrito a orillas del Mediterráneo en Italia. Todos revelan una gran sensibilidad hacia la belleza, asi como una aguda penetración en el sentido oculto de las cosas. Están completamente libres del mal humor y de la tendencia hacia una metafísica demasiado sutil que se encuentran a veces en otras obras de Lawrence. No tienen más defecto que algunos errores en el empleo de palabras españolas, los cuales podemos perdonar al autor. Aunque Lawrence era un buen lingüista, ya que sabía hablar y escribir el alemán y el italiano, sus conocimientos de español eran escasos. $Y$ como otros muchos ensayistas británicos, es posible que haya concedido menos importancia a la escueta exactitud que al encanto. Porque la verdad es que Las mañanas en México es un librito lleno de encanto y también muy instructivo. Es de lo mejor de la producción de $\mathrm{D}$. $\mathrm{H}$. Lawrence.

Eliot G. FAy, Emory University, Georgia. 
BIBLIOGRAFIA

1 Lawrence, Frieda, Not I But the Wind. New York, The Viking Press, 1934, pp. 147-148.

2 Lawrence, David Herbert, Letters, ed. by Aldous Huxley. New York, The Viking Press, 1932, pp. 627-628.

3 Ibid, p. 629.

4 Ibid., pp. 629-630.

5 Ibid., D. 630.

6 Brett, Dorothy, Lawence and Brett. Philadelphia, J. B. Lippincott Co, 1933, pp. $170-171$.

7 Lawrence, Frieda, op. cit., p. 148.

8 Lawrence, D. H., op. cit., p. 633.

9 Lawrence, Frieda, op. cit., p. 149.

10 Brett, Dorothy, op. cit., pp. 636-637.

11 Lawrence, D. H, op. cit., pp. 636-637.

12 Ibid., p. 637.

13 Lawrence, Frieda, op. cit., p. 149.

14 Loc, cit.

15 Lawrence, Frieda, op. cit., pp. 150-151.

16 Lawrence, D. H., op. cit., p. 638.

17 Loc. cit.

18 Lawrence, D. H., Mornings in Mexico. London, Martin Secker, 1927. 
